\title{
Study of clinical and epidemiological profile of thyroid swelling
}

\author{
Srivastava $\mathrm{CS}^{1}$, Saxena $\mathrm{A}^{2}$ \\ ${ }^{1}$ Dr Chandrashekhar Srivastava, Assistant Professor, Depatment of Medicine, Major S D Singh Medical college, Fatehgarh, UP, \\ India, Dr Anand Saxena, Associate Professor, Department of Surgery, L N Medical College, Bhopal, MP, India
}

Address for correspondence: Dr Chandrashekhar Srivastava, Email: Email: ccsrivastava9oct@ gmail.com

\begin{abstract}
Introduction: Thyroid swelling remains a problem of enormous magnitude all over the world. The problem in clinical practice is to distinguish reliably the few malignant tumors from the many harmless nodules so that a definitive preoperative tissue diagnosis of the malignancy allows planning of appropriate surgery and relevant patient counseling. FNAC is reliable, safe and accurate method as a first line of evaluation in thyroid swelling before the surgery. Material And Methods : The present study was conducted in Department of Medical College. It included Cross sectional study of cytomorphology of fine needle aspiration cytology material of 156 patients presenting with thyroid nodule in the Department. Information about the clinical presentation, treatment modality and presence or absence of malignancy was collected in a proforma and was analyzed. Statistical tests employed are tests of proportion, tests of percentage, Student's t-test and Fisher's exact test. Results : The commonest age group affected was 51-60 yrs. The female patients (69.8\%) outnumbered the male patients $(30.1 \%)$. The cytomorphological analysis of 156 patients revealed 10 cases of neoplastic lesions. Maximum number (122) of patients was suffering with goiter followed by lymphocytic thyroiditis (12) and nodular disease (8). Amongst the malignant cases six cases were of papillary carcinoma and six cases of follicular carcinoma. Conclusion : FNAC is a simple, safe and cost-effective diagnostic modality in the investigation of thyroid disease with high specificity and accuracy. We concluded that FNAC diagnosis of malignancy is highly significant. A benign FNAC diagnosis should be viewed with caution as false negative results do occur and these patients should be followed up and any clinical suspicion of malignancy even in the presence of benign FNAC requires surgery. So, final diagnosis and treatment pattern should be based upon histopathology.
\end{abstract}

Keywords: Thyroid swelling, Thyrood Adenoma, Thyroid tumour, Fine Needle Aspiration Cytology

\section{Introduction}

Thyroid swelling remains a problem of enormous magnitude all over the world. The problem in clinical practice is to distinguish reliably the few malignant tumors from the many harmless nodules so that a definitive preoperative tissue diagnosis of the malignancy allows planning of appropriate surgery and relevant patient counseling. The prevalence of thyroid swelling ranges from $4 \%$ to $10 \%$ in the general adult population and from $0.2 \%$ to $1.2 \%$ in children [1]. The majority of clinically diagnosed thyroid swelling are non-neoplastic; only $5 \%$ to $30 \%$ are malignant and require surgical intervention [2]. In India, thyroid cancer comprises of $1 \%$ of all head and neck cancers.

Fine needle aspiration cytology of thyroid is a well

Manuscript received: $4^{\text {th }}$ July 2015

Reviewed: $11^{\text {th }}$ July 2015

Author Corrected: $19^{\text {th }}$ July 2015

Accepted for Publication: $12^{\text {th }}$ Aug 2015 established out patient department procedure used in primary diagnosis of thyroid swellings. Fine needle aspiration cytology by giving direct morphological information often bridges the gap between clinical findings and laboratory test to give a definite diagnosis and subsequently reduce the need of surgery [3]. Definite cytological and clinical criteria have been outlined to distinguished various types of thyroid lesions [4].

Fine needle aspiration cytology is considered the gold standard diagnostic test in the evaluation of a thyroid nodule and other test like ultrasound and nuclear scan should be used in conjunction with fine needle aspiration cytology [5]. Despite high prevalence of thyroid nodule and incidental malignancies, the prevalence of clinically overt thyroid carcinoma is 
much lower. Therefore the routine use of fine needle aspiration cytology in the assessment of thyroid nodule has reduced the number of patient subjected to thyroidectomy for benign diseases of the thyroid [6].

The present study is undertaken to evaluate the accuracy of thyroid FNAC and its correlation with histopathological examination.

\section{Material Methods}

A cross sectional study was done in the department of Medicine of tertiary care teaching hospital of North India. All patients were evaluated by thorough clinical examination followed by routine investigations, FNAC and histopathological examination. The cytology reports were compared with the histological diagnosis. Sensitivity, specificity, accuracy, positive predictive value and negative predictive value were calculated.

Inclusion criteria: Those patients presenting with thyroid swelling, who underwent FNAC, thyroid surgery and histopathological examination within the study period were included in the study.

Exclusion criteria: Those patients having FNAC done but did not have thyroid surgery were excluded.

\section{Results}

Clinical and Epidemiological profile of Thyroid swelling

Table 1: Distribution of patients of thyroid swelling
All patients both male and female in the age group 1-90 years attending various departments having thyroid swellings who were referred to the pathology department for FNAC were analysed. Prior to aspiration and physical examination were carried out to note the mobility of the thyroid swelling during swallowing and presence of any cervical lymph node. All aspiration were done by cytopathologists to ensure representative sampling.

The patients were asked to lie down with a pillow beneath the chest for better visualization of the gland. Using sterile precautions FNAC was performed using nonaspiration or aspiration techniques by $23 \mathrm{G}$ needle with $10 \mathrm{ml}$ syringe. If the swelling was cystic, the cyst fluid was collected in the syringe for the preparation of smears after centrifugation The smears were either air dried or alcohol fixed (95\%). Air dried smears were stained by the MayGrunwald Giemsa stain while alcohol fixed smears were stained by the Papaniculauo method.

Statistical analysis: The data collected on Excel sheet and analyzed. Statistical tests employed are tests of proportion, tests of percentage, Student's t-test and Fisher's exact test.

\begin{tabular}{|l|l|l|l|}
\hline & Male & Female & Total \\
\hline $10-20$ & 6 & 16 & 22 \\
\hline $21-30$ & 4 & 11 & 15 \\
\hline $31-40$ & 7 & 14 & 21 \\
\hline $41-50$ & 11 & 20 & 31 \\
\hline $51-60$ & 10 & 23 & 33 \\
\hline $61-70$ & 6 & 15 & 21 \\
\hline $71-80$ & 3 & 10 & 13 \\
\hline More than 80 & 47 & 109 & 156 \\
\hline
\end{tabular}

In this study we found that out of 156 patients most of the patients are female109 [ 69.8\%] which outnumbers males 47[ $30.1 \%$ ] and most common age group affected is 51-60years followed by 41-50 years. 
Table 2: Clinical and FNAC diagnosis of Thyroid swelling

\begin{tabular}{|c|c|c|c|c|c|c|c|}
\hline \multirow[b]{2}{*}{$\begin{array}{l}\text { Clinical } \\
\text { diagnosis }\end{array}$} & \multicolumn{7}{|c|}{ FNAC diagnosis } \\
\hline & $\begin{array}{l}\text { Colloid } \\
\text { Goitre }\end{array}$ & $\begin{array}{l}\text { Nodular } \\
\text { goitre }\end{array}$ & $\begin{array}{l}\text { Graves } \\
\text { disease }\end{array}$ & Thyroiditis & $\begin{array}{l}\text { Papillary } \\
\text { carcinoma }\end{array}$ & $\begin{array}{l}\text { Follicular } \\
\text { carcinoma }\end{array}$ & $\begin{array}{l}\text { Non } \\
\text { specific }\end{array}$ \\
\hline $\begin{array}{l}\text { Colloid goitre } \\
\text { (119) }\end{array}$ & 104 & 10 & 3 & 2 & & & 3 \\
\hline $\begin{array}{l}\text { Graves disease } \\
(7)\end{array}$ & & 1 & 5 & 1 & & & \\
\hline Thyroiditis(12) & & 1 & & 11 & & & \\
\hline Carcinoma (10) & & & & & 5 & 5 & \\
\hline $\begin{array}{l}\text { Nodular disease } \\
\text { (8) }\end{array}$ & 4 & 3 & 1 & & & & 4 \\
\hline
\end{tabular}

The above table shows out of 156 patients, clinically 119 were diagnosed as colloid goitre which confirmed after FNAC in which 104 cases were colloid goitre, 10 were nodular goiter, 3 were graves disease, 2 were thyroiditis and 3 were non specific. Similarly 7 were clinically diagnosed as graves disease which after FNAC,5 turned out to be graves disease and 1 each of nodular goiter and thyroiditis.

Clinically 12 were diagnosed as thyroiditis, after FNAC , 11 of them were thyroiditis and 1 became nodular goiter. similarly 10 and 8 patients were clinically diagnosed as carcinoma and nodular disease respectively which after FNAC of carcinoma patients 5 were papillary and 5 were follicular carcinoma andAfter FNAC of 8 nodular disease , 4 of them were colloid goiter, 3 were nodular goiter, 1 was graves disease, and 4 were non specific swelling.

Table 3: FNAC diagnosis and Histological confirmation

\begin{tabular}{|l|l|l|l|l|}
\hline FNAC diagnosis & Histological diagnosis & Podular disease & Papillary carcinoma & Follicular carcinoma \\
\hline & Colloid Goitre & 3 & & \\
\hline Colloid goitre (43) & 40 & 3 & & \\
\hline Nodular disease (7) & 2 & 5 & 5 & 1 \\
\hline $\begin{array}{l}\text { Papillary Carcinoma } \\
(6)\end{array}$ & & & 0 & 6 \\
\hline $\begin{array}{l}\text { Follicular carcinoma } \\
(6)\end{array}$ & & & & 6 \\
\hline
\end{tabular}

The above study showed, out of 43 cases of colloid goiter on FNAC, 40 cases showed colloid goiter, 2 cases showed nodular disease on histological confirmation. out of 6 cases of papillary carcinoma on FNAC, 5 cases showed papillary carcinoma and 1 showed follicular carcinoma. Out of 7 nodular disease, 2 were of colloid goiter and 5 were nodular disease on histological confirmation. out of 6 cases of follicular carcinoma, all the 6 cases were histologically correlated. Sensitivity calculated for colloid goiter by FNAC is $93 \%$.

\section{Discussion}

Thyroid nodules are very common occurring in $4 \%$ of the population aged between 30 and 60[1]. Most of the swellings are benign only between $10 \%$ to $20 \%$ are malignant [7]. Thyroid enlargement whether diffuse or in the form of a nodule, leads to a battery of investigations mainly to rule out the possibility of neoplasm or thyroiditis [6].

Fine needle aspiration cytology (FNAC) is usually the first line of investigation and the other investigations are done subsequently with an aim to select patient who require surgery and those that can be managed conservatively. Fine needle aspiration cytology is inexpensive, can be performed in a out patient clinic and has few complications including absence of tumor implants along the needle tract [8].

In the present study age of the patients ranged from 190 years. Most commonly affected age group is 51-60 years which is comparable to study done by Monoj Gupta,Sabita Gupta and Ved Bhushan Gupta( 2010) [5] and the study done by Bhatia et al 2007 [10]. Female predominance has been observed in present study similar to other studies $[6,10,11]$. 
$\mathrm{T} \mathrm{T}$, et al[12] found highest (45.2\%) incidence of thyroid swellingin the 41-60 year age group, followed by $42.9 \%$ in the $21-40$ yearage group, $8.1 \%$ in the $>60$ years age group, and $3.8 \%$ in the agegroup $<21$ years. Females predominated in present study, $87 \%$ females and $13 \%$ males, ratio being 7:1. They also revealed similarfindings to this study.

In the present study most common non neoplastic lesion is the colloid goitre which is similar to the studies done by other authors [3]. Papillary carcinoma of thyroid is the most commonly encountered neoplasm in our study which is similar to studies done by and Tabaqchali et al [13].

FNAC is regarded as the gold standard initial investigation in the diagnosis of thyroid swellings. The technique is safe, simple and quick with a low complication rate.FNA cytology of the thyroid has a high negative predictive value, which is useful to reassure the majority of patients presenting with thyroid enlargement. However, a negative FNA should never exclude malignancy if there is a strong clinical suspicion. If this rule is adhered to a large number of patients will be spared unnecessary surgery and no malignant nodule will go untreated[14]Several other tests, such as high resolution ultrasonography, radioisotope scanning and FNA biopsy Have been used for evaluation of thyroid swellings before proceeding to thyroid surgery[15]. Studies have demonstrated that among all these diagnostic modalities, FNAC is the most accurate, cost effective screening test for rapid diagnosis of thyroid swelling. FNAC of the thyroid nodule is reported to have sensitivity ranges from $65 \%$ to $98 \%$ and specificity of $72 \%$ to $100 \%$. FNAC has beenshown to have similar or higher sensitivity and accuracy levels than frozen section examination[16].

Karma et al[17] did the cytomorphological analysis of 206 patients revealed 190 cases $(92.2 \%)$ of neoplastic lesions, 10 cases $(4.8 \%)$ were neoplastic and 6 cases (2.9\%) had indeterminate cytomorphology. Maximum number $(65.5 \%)$ of patients was suffering with goiter followed by lymphocytic thyroiditis $(26.2 \%)$. In our study we also found that maximum no. of patients suffering from colloid goiter followed by lymphocytic thyroiditis.

Vyas $\mathrm{C}$ et al[18] found that Females predominated in this study $87 \%$, ratio being 7:1. Majority (40\%) of patients came with complaint of swelling of duration less than 6 months, similar to our study.
Parikh U.R et al[19] studied FNAC analysis showed 93.67\% (207 cases) non-neoplastic lesions, 3.62\% (8 cases) neoplastic lesions and $2.71 \%$ (6 cases) malignant lesions. Histopathological analysis showed $81.3 \%$ (100 cases) non neoplastic lesions and $18.70 \%$ (23 cases) neoplastic lesions. Commonest malignancy detected is papillary carcinoma of thyroid in 5 cases. The accuracy rate of FNAC in diagnosis for non-neoplastic, neoplastic and malignant lesions were 90\%, $85.71 \%$ and $100 \%$ respectively.In our study also commonest malignancy detected was papillary carcinoma.

Borgohain R et al [20]concluded that FNAC diagnosis of malignancy is highly significant. A benign FNAC diagnosis should be viewed with caution as false negative results do occur and these patients should be followed up and any clinical suspicion of malignancy even in the presence of benign FNAC requires surgery. So, final diagnosis and treatment pattern should be based upon histopathology

KhageswarRout[21] found that Colloid goiter was most common among the thyroid swelling (42.2\%) followed by colloid goiter with Cystic degeneration (13.2\%). In this study 53 cases were females and 23 were males and peak age of incidence was in second and third decades of life It is contradicting with study by Bhansali [22] where it was the fifth decade of life. The female to male ratio is $2.3: 1$ and our study.

\section{Conclusion}

FNAC is a simple, safe and cost effective modality in investigation of thyroid disease with high accuracy and specificity. It is very much helpful in third World Countries like India. The suspicious indeterminate results prove to be an area of uncertainty which can be resolved by surgical resection and biopsy.

\section{Funding: Nil, Conflict of interest: Nil, Permission from IRB: Yes}

\section{References}

1. Burch HB, Burman KD, Reed HI, Buckner L, Raber T, Ownbey Jl. Fine needle aspiration of thyroid nodules. Determinants of insufficiency rate and malignancy yield at thyroidectomy. Acta Cytol. 1996 Nov-Dec;40(6):1176-83. 
2. Gharib H, Goellner JR. Fine-needle aspiration biopsy of the thyroid: an appraisal. Ann Intern Med. 1993 Feb 15;118(4):282-9.

3. Devi , Aziz . Cytomorphological Evaluation And Thyroid Function Test (Tft) Analysis In Various Thyroid Diseases "Our Experience At Tertiary Care CenterInternational Journal of Medical Science and Clinical Inventions Volume 1 issue 82014 page no. 387-392 ISSN: 2348-991X.

4. Mehdi S,Vsenwala S, Zheer M, Vasenwala A. Role of FNAC and antithyroid antibodies in the diagnosis of thyroid disorders. Indian J Pathol Microbiol. 2003 Apr;46(2):184-90.

5. Monoj Gupta ,Savita Gupta, and Ved Bhushan Gupta."Correlation of Fine Needle aspiration Cytology with Histopathology in the Diagnosis of Solitary Thyroid Nodule".Journal of Thyroid Research Volume 2010,Article ID 379051,5 pages doi:10.4061/2010/379051

6. Sukant Garg ,Uma Handa, Harsh Mohan, Nitin Nagarkar. Role of fine needle aspiration cytology in diagnosis and management of thyroid lesions: A study on 434 patients. Journal of Cytology.2008;25(1):13-17.

7. Franklyn JA, Sheppard MC. The value of imaging in the diagnosis of thyroid cancer. Nucl Med Commun. 1992 Sep;13(9):641-3.

8. Leonard N, Melcher DH. To operate or not to operate? The value of fine needleaspiration cytology in assessment of thyroid swelling . J Clin Pathol. 1997 Nov;50(11):941-3.

9. A. Bhatia, A .Rajwanshi, R.J. Dash, B.R. Mittal and A. K Saxena, "Lymphocytic Thyroiditis- is cytological grading significant? A correlation of grade with clinical, biochemical, Ultrasonographic and radionuclide parameters, ”CytoJournal, vol.4, article 10,2007

10. Neelam Sood and Jitendra Singh Nigam . "Correlation of Fine Needle Aspiration Cytology Findings with Thyroid Function Test in Cases of Lymphocytic Thyroiditis". Journal of Thyroid Research Volume 2014,Article ID 430510,5pages.http://dx.doi.org/10.1155/2014/430510 14.
11. B.N. Gayathri, R Kalyani, M.L Harendra Kumar, and K Krishna Prasad, "Fine needle aspiration cytology of Hashimoto's thyroiditis -a diagnostic pitfall with review of literature," Journal of Cytology, vol.28 no.4,pp 210-213, 2011. Available on http://www.ncbi.nlm.nih.gov/

12. Htwe T T, Hamdi M M, Swethadri G K, Wong J O L, Soe M M, Abdullah M S; Incidence of thyroid malignancy among goitrous thyroid lesions from the Sarawak General Hospital 2000-2004. Singapore Med J. 2009 Jul;50(7):724-8.

13. Tabaqchali MA et al. Thyroid aspiration cytology in Newcastle. Ann R Coll Surg Engl. 2000 May;82(3):149-55.

14. Leonard N, Melcher DH. To operate or not to operate? The value of fine needleaspiration cytology in assessment of thyroid swelling .Jc Clin pathol 1997;941-943. Available on http://www.ncbi.nlm.nih.gov/

15. B. Mundasas, I. Macllister, J. Carson, P. C. Pyper. Accuracy of fine needle aspiration cytology in diagnosis of thyroid swellings. The Internet Journal of Endocrinology, 2006; Vol. 2; Mo. 2.

16. H. A. Nggada, A. B. Musa, B. M. Gali \& M. I. Khalil : Fine Needle Aspiration Cytology Of Thyroid Nodule(S): A Nigerian Tertiary Hospital Experience . The Internet Journal ofPathology.2006 Volume 5 Number 1.avilable on www.scirp.org/journal

17.TKamra , Agarwal R et al. Evaluation Profile of Thyroid Nodule by Fnac in the Rural Population of Khanpur Kalan, Sonepat, Haryana. Journal of Clinical and Diagnostic Research. 2014 Oct, Vol-8(10): FC16FC18. DOI: 10.7860/JCDR/2014/9134.4977

18. Vyas.C, Vijayvargiya S.A study of thyroid swelling with clinicopathological parameters. Int $\mathrm{J}$ Biol Med Res. 2013; 4(2) : 3250 - 3252.avilable on www.biomedscidirect.com

19. Parikh UR, Goswami HM. Fine Needle Aspiration Cytology (FNAC) Study of Thyroid Lesions GUJARAT MEDICAL JOURNAL / AUGUST-GMJ 262012 Vol.67 No.2 available on medind.nic.in. 
20. Borgohain1 R, Lal R et al A Study of CytoHistological Correlation in the Diagnosis of Thyroid Swelling. IOSR Journal of Dental and Medical Sciences (IOSR-JDMS) e-ISSN: 2279-0853, p-ISSN: 22790861. Volume 13, Issue 11 Ver. IV (Nov. 2014), PP 4649 www.iosrjournals.org

21. Rout K , Ray CS, Behera SK, Biswal R. Comparative Study of FNAC and Histopathology of
Thyroid SwellingsIndian J Otolaryngol Head Neck Surg. 2011 Oct; 63(4): 370-372. doi: 10.1007/s12070011-0280-0

22. Bhansali SK. Fine needle aspiration versus frozen section diagnosis. Arch Otolaryngol Head Neck Surg.1982;112:867-869.

\section{How to cite this article?}

Srivastava CS, Saxena A. Study of clinical and epidemiological profile of thyroid swelling. Int J Med Res Rev 2015;3(8):783-788. doi: 10.17511/ijmrr.2015.i8.147. 